\title{
Removal of Trimethylamine from Indoor Air Using Potted Plants under Light and Dark Conditions
}

\author{
Tatiya Wannomai ${ }^{1 \dagger}$, Patiya Kemacheevakul ${ }^{1,2^{*}}$, Paitip Thiravetyan ${ }^{3}$ \\ ${ }^{I}$ Department of Environmental Engineering, Faculty of Engineering, King Mongkut's University of Technology Thonburi, \\ Bangkok 10140, Thailand \\ ${ }^{2}$ Center of Excellences on Hazardous Substance Management (HSM), Bangkok 10330, Thailand \\ ${ }^{3}$ School of Bioresources and Technology, King Mongkut's University of Technology Thonburi, Bangkok 10150, Thailand
}

\begin{abstract}
A phytoremediation was evaluated as a solution for mitigating the fishy odor, or trimethylamine (TMA), that occurs in the seafood industry, including fresh markets. A synthetic TMA chemical was used to generate the fishy odor, and eight types of potted plants-Prickly pear cactus, Dracaena sanderiana Sander, Dieffenbachia camilla, Tradescantia spathacea, Peperomia magnoliifolia, Chlorophytum comosum, Cereus hexagonus (L.) Mill., and Scindapsus aureus-were selected as candidates for removing TMA in light and dark conditions. The results showed that $S$. aureus had the highest TMA removal efficiency in light conditions after $72 \mathrm{~h}(>95 \%)$. However, it had very low efficiency under dark conditions, suggesting that $S$. aureus should be placed in locations with all-day light sources. On the other hand, cactus types (C. hexagonus (L.) Mill. and Prickly pear cactus) are highly efficient at removing TMA in both light and dark conditions after $72 \mathrm{~h}(>90 \%)$ and may therefore be more suitable for real-world environments containing both light and dark conditions.
\end{abstract}

Keywords: Fishy odor; Phytoremediation; Trimethylamine; Potted plant; Light conditions.

\section{INTRODUCTION}

Trimethylamine (TMA, $\left.\mathrm{N}\left(\mathrm{CH}_{3}\right)_{3}\right)$ is a gaseous organic compound at room temperature (Chung and Lee, 2009). It is a colorless gas with a fishy odor at low concentrations and can change to ammonia-like odor at higher concentrations (OSHA, 1994; Kim et al., 2011; Boraphech and Thiravetyan, 2015). Degradation of plants and animal residuals by microorganisms, especially rotting marine animals, produce TMA (Zhu et al., 1997; Chien et al., 2000; Chang et al., 2004; Chung and Lee, 2009). The offensive odor can affect human's health when they live in unpleasant smell area for a long period. The major adverse health impacts from inhalation exposures are breathing difficulty, irritation of upper respiratory tract, coughing, and even death (Chien et $a l ., 2000)$. Exposure dose is one of the factors, which affects

\footnotetext{
${ }^{\dagger}$ Now at Department of Transdisciplinary Science and Engineering, School of Environment and Society, Tokyo Institute of Technology, Tokyo 152-8552, Japan

* Corresponding author.

Tel.: 66(0)-2-470-9360; Fax: 66(0)-2-470-9165

E-mail address: patiya.kem@kmutt.ac.th
}

human health (Geraets et al., 2014). The National Institute for Occupational Safety and Health (NIOSH) recommended that $10 \mathrm{ppm}$ is a recommended exposure limit (REL) for TMA (NIOSH, 1981). TMA is one of air pollution problem because it causes unpleasant smell at low concentrations (Wolverton et al., 1989; Ding et al., 2007; Sintermann et al., 2014). Hence, mitigation of odor problem can help to improve human's life. There are many methods to eliminate or reduce the odor problem, such as absorption, biofiltration, and phytoremediation. Phytoremediation is a good alternative method to solve this problem (Ding et al., 2007) because this method is not expensive, environmentally friendly, highly efficient, and acceptable (Wolverton et al., 1989; Wolverton, 1996; Nobel, 1999; Wood et al., 2001).

Since the 1990s, purification of offensive odor chemicals using houseplants has been studied by National Aeronautics and Space Administration, or NASA (Oyabu et al., 2003). After NASA's experiments, purification of these chemicals using houseplants has emerged as a well-known method. Wolverton et al. (1993) mentioned that these offensive odor chemicals, such as formaldehyde, xylene, and ammonia, in an indoor environment were removed by plant and soil microorganisms. Oyabu et al. (2001) also reported that toluene, formaldehyde, and xylene were cleaned from ambient air by plants. Moreover, purification of contamination in soils, sludge, sediments, surface water, 
or ground water can be done by a phytoremediation process (U.S. EPA, 1999). Phytoremediation is a natural process which consists of several mechanisms such as phytoextraction, phytostabilization, phytovolatilization, rhizofiltration, biosorption, phytostabilization, phytovolatilization, phytodegradation, and phytostimulation (Torok et al., 2015). The treatment efficiency of each mechanism depends on the properties, and physical, chemical, and biological characteristics of each pollutant (U.S. EPA, 1999; Turker et al., 2013; Torok et al., 2015).

Plants play the major role in phytoremediation process. Normally, plants are living things which produce their food by photosynthesis process. Green plants transform solar energy to chemical energy through this process. Therefore, the photosynthesis is a main process for plants, which can be affected by various kinds of light sources (Taiz and Zeiger, 1998). The sunlight and lamps can be the representative of light sources. Moreover, the different wavelengths of light sources can be applied for plants (Morh and Browese, 1995). Light-emitting diode (LED) lamp is a good alternative of light source (Nhut et al., 2003; Chung et al., 2010; Yurio et al., 2011; Lin et al., 2013). It is probable that under LED conditions, plants will increase the purification efficiency of odor chemicals (Chen et al., 2014).

Several research studies have reported the removal of odorous chemicals and volatile pollutants (Drozdova et al., 2001; Yang et al., 2009; Turkey et al., 2013; Torok et al., 2015). However, few researchers have studied TMA. Therefore, the aim of this research was to remove TMA from indoor air using potted plants under dark and different light conditions. In terms of light conditions, fluorescent and LED lamps were used. The concentration of TMA was continuously measured using gas chromatography (GC).

\section{METHODS}

\section{Preparation of Plants and Reactors}

Eight species of potted plants were selected for this research, which were Prickly pear cactus, D. sanderiana Sander, S. aureus, Dieffenbachia camilla, T. spathacea, Peperomia magnoliifolia, Chlorophytum comosum, and $C$. hexagonus (L.) Mill. Two species among eight plants were cactus (Prickly pear cactus and C. hexagonus (L.) Mill.) with others as leaf plants. Eight species of potted plants were selected based on the removal rate of ammonia and size of potted plants. In these experiments, the efficiency of TMA removal by aerial parts of plants was investigated. Therefore, root parts were covered by aluminum foil. The surface area of leaves was selected around $130-150 \mathrm{~cm}^{2}$ for each plant (Treesubsuntorn and Thiravetyan, 2012; Boraphech and Thiravetyan, 2015).

The glass desiccators were selected as the reactors for indoor air condition. The volume of each desiccator was 15.6 L with cover lid (Fig. 1). The cover lid was used to control TMA concentration and take the samples. Gas sampling was sucked by glass syringe through the septum on top of the cover lid. Moreover, greases and parafilm were applied for gas leak protection (Boraphech and
Thiravetyan, 2015).

\section{Preparation of TMA}

TMA is a fishy odor. The critical concentration for living organism is $150 \mathrm{ppm}$ in $30 \mathrm{~min}$ (Boraphech and Thiravetyan, 2015; Ruijten, 2005; U.S. EPA, 2016). Hence, the concentration of TMA which was used in this research was $150 \mathrm{ppm}$. TMA (40\% aqueous solution) was obtained from Sigma Aldrich. The volume of TMA solution was calculated from Eqs. (1)-(3):

$$
\begin{aligned}
& \text { ppm }=10^{6} \times \frac{W}{M_{w}} \times \frac{M_{C}}{V} \\
& M_{c}=24.47 \times \frac{760}{P} \times\left(\frac{T+273.15}{298.15}\right) \\
& \rho=\frac{W}{V_{g}}
\end{aligned}
$$

where $\rho$ is the density of TMA $\left(1.88 \mathrm{~g} \mathrm{~mL}^{-1}\right), V_{g}(\mathrm{~mL})$ is TMA volume, $M_{w}\left(\mathrm{~g} \mathrm{~mole}^{-1}\right)$ is molecular weight of TMA, $M_{C}$ is mole concentration, $\mathrm{V}$ is volume of glass chamber $(15.6 \mathrm{~L}), P$ is pressure $(\mathrm{mmHg}), T$ is temperature $\left({ }^{\circ} \mathrm{C}\right)$, and $W$ is TMW weight $(\mathrm{g})$.

From Eq. (4), the TMA which uptake by plant leaves was calculated by using plant leaf area. Therefore, the molar concentration is expressed as nmol per unit area (Wararat et al., 2014):

TMA removal per leaf area $\left.(\mathrm{nmol} \mathrm{cm})^{-2}\right)=\frac{C_{i}-C_{f}}{A}$

where $C_{i}$ is initial concentration (nmol), $C_{f}=$ final concentration (nmol), and $A=$ total leaf area $\left(\mathrm{cm}^{2}\right)$.

\section{TMA Removal Experiments under Different Light Conditions}

Three conditions were set in these experiments, which were light and dark conditions. For light conditions, a LED lamp (200 lux) which was $6500 \mathrm{~K}$ daylight $(6 \mathrm{~W}, 50 / 60 \mathrm{~Hz}$, $45 \mathrm{~mA}$ ) was selected as a kind of light source because this

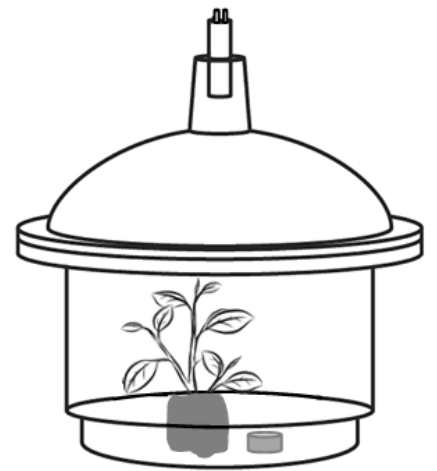

Fig. 1. Reactor for indoor air condition. 
type of light source is suitable for plants and uses less electricity than other types (Taiz and Zeiger, 1998; Tang et al., 2010; Yorio et al., 2011). The second condition was fluorescent condition. Both sources are common light sources in an indoor condition such as houses and offices. The last condition was dark conditions. The experiments were conducted under dark condition. Each desiccator was covered by two black bags for light protection.

The selected plants were placed in each desiccator. TMA was injected into the foil cup near the selected plant. The experiments at different conditions were tests for $72 \mathrm{~h}$ at $25 \pm 2{ }^{\circ} \mathrm{C}$. The duplicate experiments were conducted for accuracy of results. Air samples were analyzed at 0, 2, 4, $8,12,24,48$, and $72 \mathrm{~h}$. The concentration of TMA was measured by using GC (Boraphech and Thiravetyan, 2015).

\section{Gas Chromatography Analysis}

The CP-Volamine GC Column (GC-6890N, Agilent) was used to analyze TMA concentration by GC (Chung and Lee, 2009). The condition of GC is shown in Table 1. A flame ionization detector (FID) was selected as a gas detector because TMA solution was a substance that can be burnt by flame (Chien et al., 2000).

\section{Cuticle Wax Extraction}

The amount of cuticle wax of all eight potted plants was determined. The leaves of each type of plants were cut into small pieces $\left(1 \times 1 \mathrm{~cm}^{2}\right)$ and put into glass bottles. The total surface area of leaves for each type of plants was around $130 \mathrm{~cm}^{2}$. The method of cuticle wax extraction was adopted from Richardson method (Richardson et al., 2005; Boraphech and Thiravetyan, 2015). Methanol and chloroform were used as the solvents for extraction at ratio of 1:1 by volume. Methanol $(30 \mathrm{~mL})$ and chloroform $(30 \mathrm{~mL})$ were poured into the bottle of each sample. In order to completely extract the wax, the prepared samples were shaken at $240 \mathrm{rpm}$ for $8 \mathrm{~h}$. After shaking process, the solvents were evaporated in each bottle around $12-16 \mathrm{~h}$ in fume hood. The remaining part was only wax.

\section{RESULTS AND DISCUSSION}

\section{TMA Removal Efficiency by Plants under Different Light Conditions}

Eight species of plants with different characteristics, such as thickness and roughness of leaves and quantity of wax in leaves, were screened (Ruijten, 2005; Boraphech and Thiravetyan, 2015). The photos and characteristics of selected plants are shown in Table 2. The experiments were conducted in the desiccators. Therefore, the height of plants could not exceed $20 \mathrm{~cm}$. The duration time for each experiment was $72 \mathrm{~h}$.

\section{TMA Removal by Plants under LED Condition}

Eight species of potted plants were placed in desiccators with TMA at $150 \mathrm{ppm}$ under LED conditions. The results in Fig. 2(a) show that C. hexagonus (L.) Mill. and S. aureus had high TMA removal efficiency. Both types of plants could decrease TMA concentration in desiccators, which
Table 1. Condition of GC instrument.

\begin{tabular}{lll}
\hline Inlet & Temp. & $200^{\circ} \mathrm{C}$ \\
& Total flow & $40 \mathrm{~mL} \mathrm{~min}^{-1}$ \\
& Split ratio & $5: 1$ \\
Column & Carrier gas & $\mathrm{He}$ \\
& Column flow & $3 \mathrm{~mL} \mathrm{~min}$ \\
& Temp. & $200^{\circ} \mathrm{C}$ \\
Detector & Detector & FID detector \\
& Temp. & $240^{\circ} \mathrm{C}$ \\
& Flaming gas & \\
& - $\mathrm{H}_{2}$ & $35 \mathrm{~mL} \mathrm{~min}^{-1}$ \\
& -Air zero & $400 \mathrm{~mL} \mathrm{~min}^{-1}$ \\
& Make up gas $\left(\mathrm{N}_{2}\right)$ & $20 \mathrm{~mL} \mathrm{~min}^{-1}$ \\
\hline
\end{tabular}

was more than $80 \%$ within $8 \mathrm{~h}$. After $72 \mathrm{~h}$ of experiments, S. aureus was the best species for TMA removal (95.4 \pm $4.6 \%$ ) and the second one was C. hexagonus (L.) Mill. $(93.6 \pm 1.3 \%)$ as shown in Fig. 2(a). It implied that both potted plants could uptake TMA at a higher rate compared to other plants. Moreover, $S$. aureus is well known as a plant which can treat pollutants including ammonia in offices and restrooms. On the other hand, C. comosum, D. camilla, and $P$. magnoliifolia had low TMA removal efficiencies which were less than $41 \%$ within $8 \mathrm{~h}$. However, the removal efficiency of these three plants increased continuously (more than $80 \%$ within $72 \mathrm{~h}$ ).

The results indicated that light sources (LED lamp) affected photosynthesis of plants (Morh and Browese, 1995; Nhut et al., 2003; Chung et al., 2010) and resulted in decreasing TMA concentrations. In addition, the removal efficiency of TMA of each plant also depends on plant species and their waxes. Normally, sunlight is a suitable light source for plants. It was quite similar to LED lamp conditions because of its wavelength. LED lamp has vital rays for plant growth at $450 \mathrm{~nm}$ (blue light), and $650 \mathrm{~nm}$ (red light) as sunlight conditions. Comparison among fluorescent lamp, LED lamp, and incandescent lamp, the proper light source which is good for growing plants is LED lamp (Morh and Browese, 1995; Taiz and Zeiger, 1998). In terms of incandescent lamp, its spectrum is quite fit for plant growth (blue and red light). However, incandescent lamp consumes much electric power and it is too hot when it is used for a long time (Morh and Browese, 1995).

\section{TMA Removal by Plants under Fluorescent Condition}

From the results in the Fig. 2(b), Prickly pear cactus, $S$. aureus, T. spathacea, C. hexagonus (L.) Mill., and $D$. camilla could decrease TMA concentration which was more than $50 \%$ within 8 h. After 24 h of experiments, Prickly pear cactus was the best species for TMA removal $(100 \pm 0 \%)$. Moreover, after $72 \mathrm{~h}$ of experiments (Fig. 2(b)), plants which could reach $100 \%$ removal were Prickly pear cactus, Peperomia magnoliifolia, C. hexagonus (L.) Mill., S. aureus, and $T$. spathacea. So, the result implied that Prickly pear cactus which is grouped in CAM plant was the best plant to remove TMA concentration in this condition. The rate of TMA removal at $8 \mathrm{~h}$ under fluorescent condition was lower than the rate of TMA removal under LED condition. 
Table 2. Details and characteristic of selected plants.

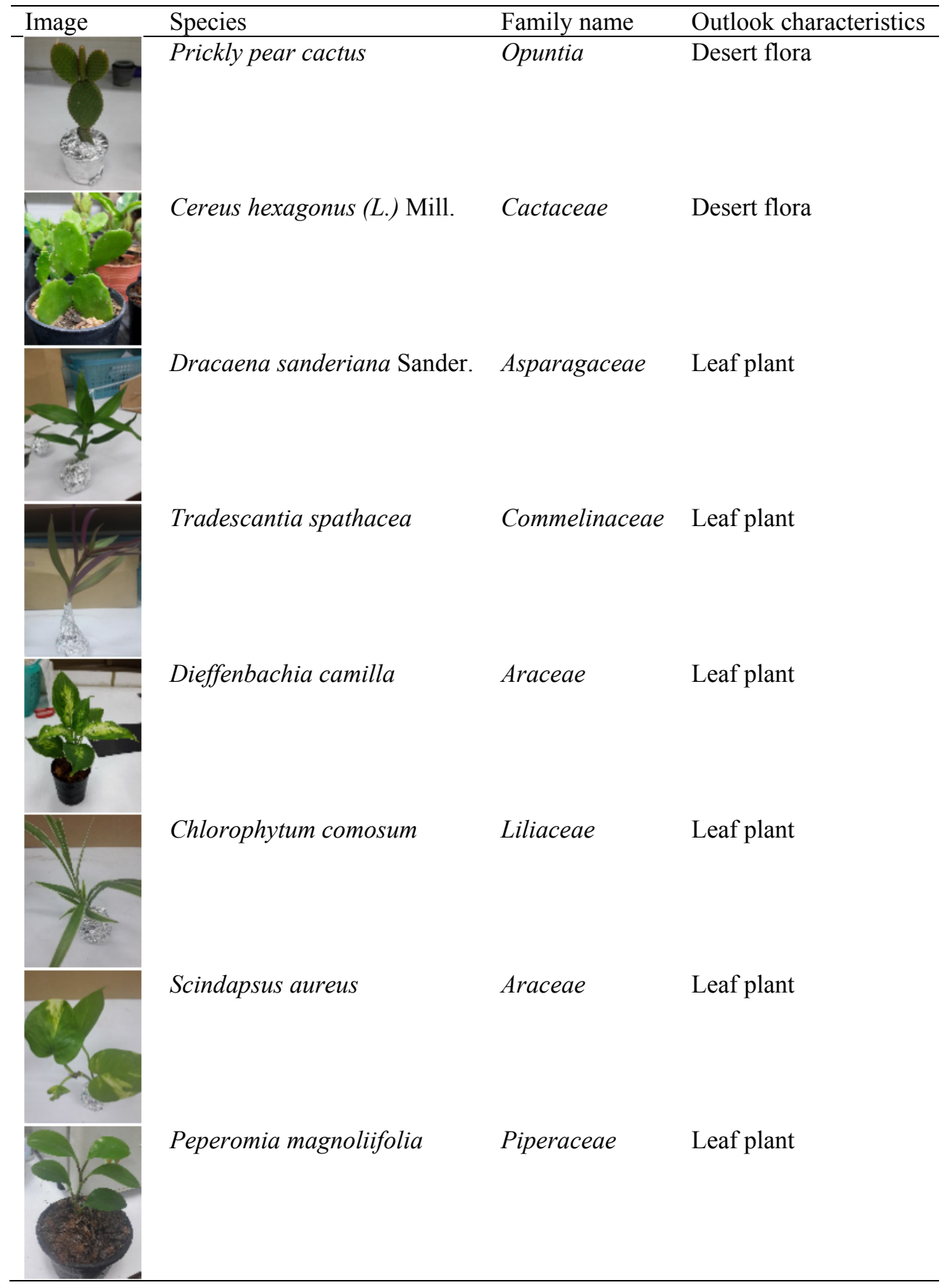

\section{TMA Removal by Plants under Dark Condition}

Fig. 2(c) shows removal of TMA in the desiccators after treatment by eight potted plants under dark conditions for 72 h. The result showed that $C$. hexagonus (L.) Mill. and Prickly pear cactus were the suitable potted plants for TMA removal under dark conditions among the eight species. Both types of plants could decrease TMA concentration, which was between $50 \%$ and $65 \%$ within $8 \mathrm{~h}$. CAM is good at adapting itself in a condition which has no light. The efficiency was not different when compared to the potted plants under light conditions. However, the efficiencies of both plants trended to increase after $72 \mathrm{~h}$ of experiments which were
$87.9 \pm 2.7 \%$ and $90.9 \pm 0.1 \%$ for Prickly pear cactus and C. hexagonus (L.) Mill., respectively. Both plants had high removal efficiency under dark conditions. The reason was Prickly pear cactus and C. hexagonus (L.) Mill. (CAM plant) open stomata at night and absorb TMA. Moreover, they had fleshy pads which look like leaves and have several functions such as water storage, photosynthesis and flower production (Boraphech and Thiravetyan, 2015; Taiz, 1998). On the other hand, $S$. aureus had the lowest TMA removal efficiency at $72 \mathrm{~h}(57.2 \pm 1.9 \%)$. It indicated that $S$. aureus preferred light for its activity because it had the highest TMA removal efficiency at $72 \mathrm{~h}$ under light conditions. 
(a)

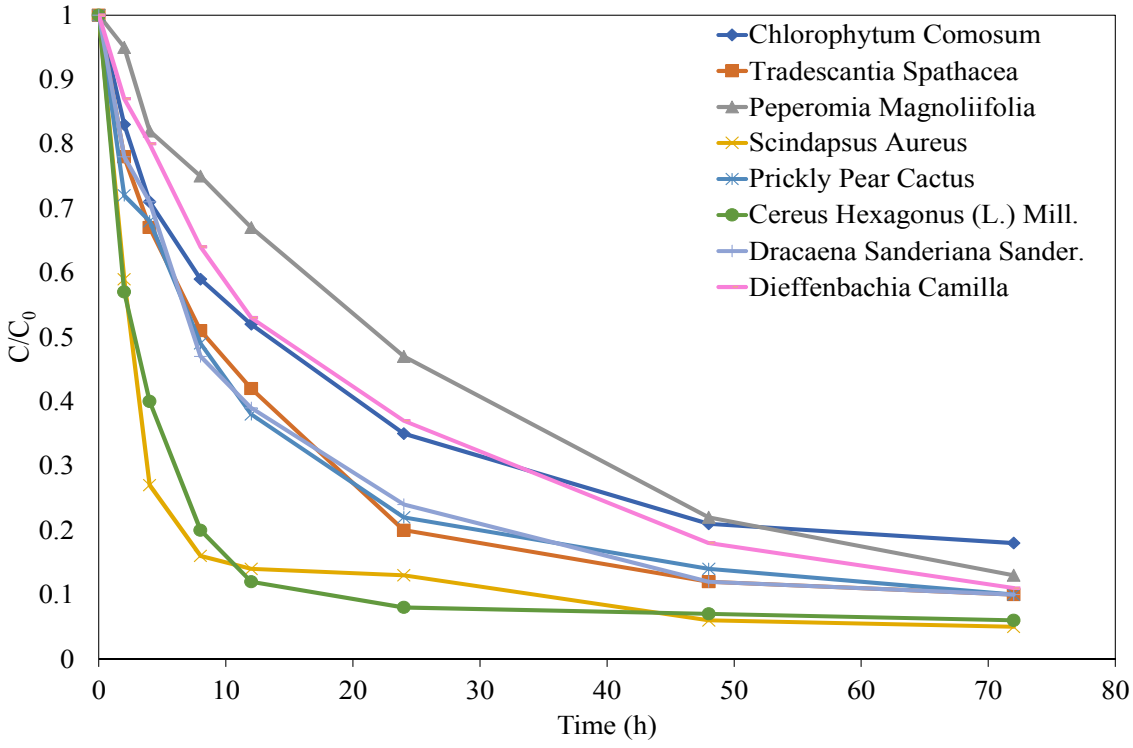

(b)

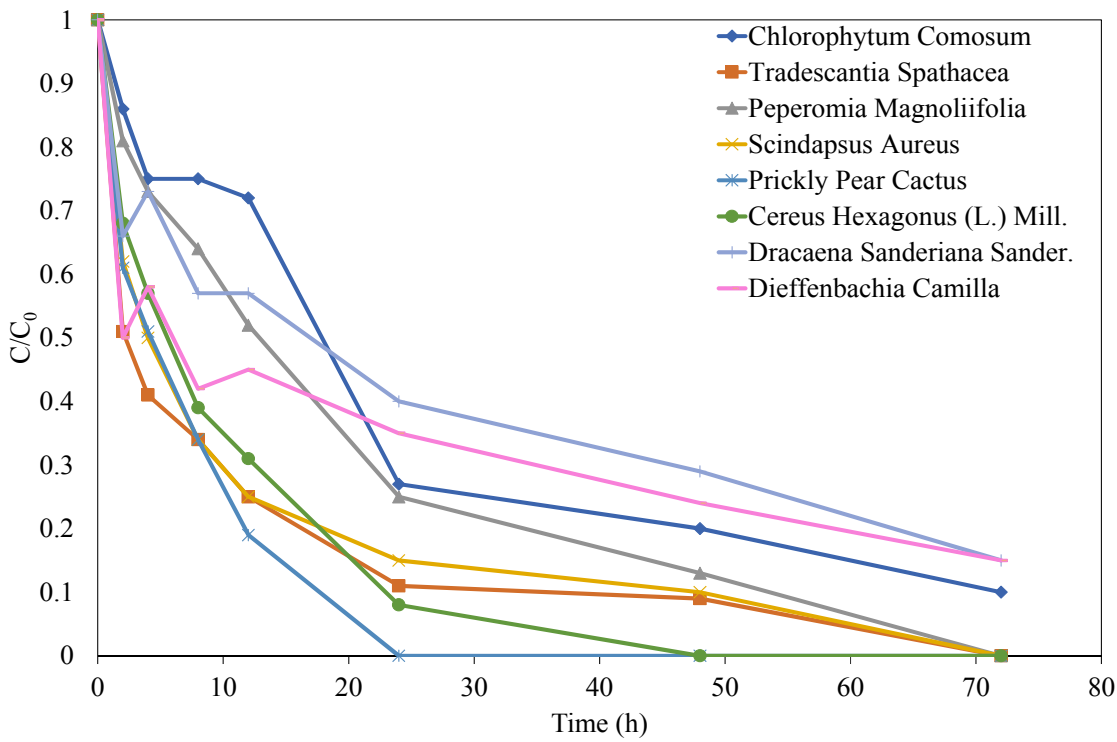

(c)

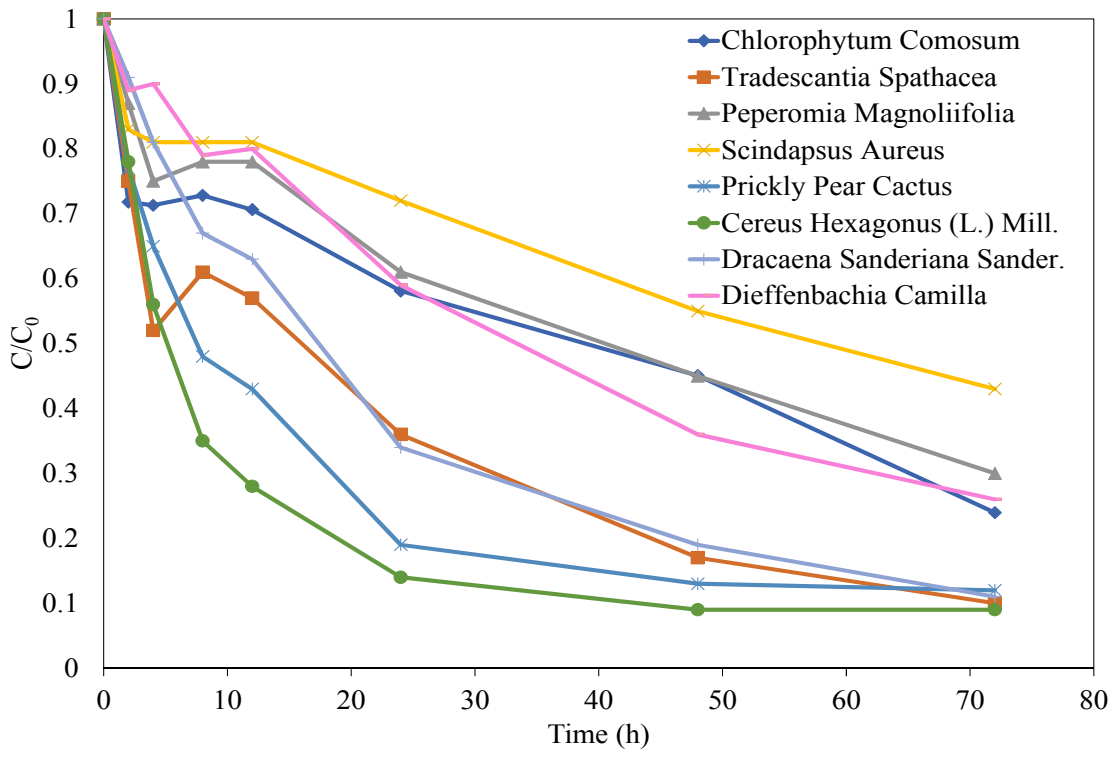

Fig. 2. Removal of TMA by various potted plants under (a) LED condition, (b) fluorescent condition, and (c) dark condition $\left(\mathrm{C}_{0}=\right.$ initial TMA concentration (ppm), $\mathrm{C}=$ remaining TMA concentration at different time $\left.(\mathrm{ppm})\right)$. 


\section{Quantity of Cuticle Wax}

The cuticle wax quantities of eight kinds of potted plants were studied by using Richardson method (Richardson et al., 2005; Boraphech and Thiravetyan, 2014). The result showed that $D$. sanderiana Sander had the highest wax concentrations $\left(7.06 \mathrm{mg} \mathrm{cm}^{-2}\right)$ as shown in Fig. 3. The second and third plants were Prickly pear cactus $\left(2.86 \mathrm{mg} \mathrm{cm}^{-2}\right)$ and $C$. hexagonus (L.) Mill. (1.17 $\left.\mathrm{mg} \mathrm{cm}^{-2}\right)$. The remaining potted plants (T. spathacea, C. comosum, D. camilla, and $S$. aureus) had low wax concentrations which were lower than $1 \mathrm{mg} \mathrm{cm}^{-2}$ with the lowest wax concentrations for $S$. aureus $\left(0.56 \mathrm{mg} \mathrm{cm}^{-2}\right)$.

Considering wax quantities of eight plants under dark conditions at $8 \mathrm{~h}$, the results showed that quantity of wax had a significant effect on TMA removal efficiency (Boraphech and Thiravetyan, 2015). Two plants (Prickly pear cactus, and $C$. hexagonus (L.) Mill.) with high amounts of wax in the leaves had the highest TMA removal efficiency. It was consistent with the study by Treesubsuntorn et al. (2012) who reported that $46 \%$ of total benzene uptake was by crude wax of $D$. sanderiana Sander at $72 \mathrm{~h}$. The results suggested that the crude wax could act as a biosorbent. The crude wax can be one important factor for adsorbing air pollutants (Treesubsuntorn and Thiravetyan, 2012). Moreover, a previous study from Treesubsuntorn et al. (2015) suggested that not only the quantity of wax but also the composition of wax affects pollutant adsorption.

\section{Comparison of TMA Removal by Plants under Light and Dark Conditions}

Based on the results from previous sections, the selected plants could be divided into two groups: (i) high removal efficiency under light conditions and (ii) high removal efficiency under light and dark conditions.
High Removal Efficiency under Light Conditions

The plants in this group $\left(\mathrm{C}_{3}\right.$ plants), which were $C$. comosum, D. camilla, P. magnoliifolia, and $S$. aureus, had high removal efficiency under light conditions but had low removal efficiency under dark conditions. The results showed that they had a very high TMA removal efficiency under light conditions at $72 \mathrm{~h}$ ( $>80 \%$ removal), especially $S$. aureus had the highest removal efficiency $(95.4 \pm 4.6 \%)$, as shown in Fig. 2 and Table S1. However, they had quite low removal efficiency under dark conditions $(<60 \%$ at 24 h) as shown in Fig. 4.

It indicated that these plants need light source for their photosynthesis (Wolverton et al., 1989; Yang et al., 2009) and enhanced TMA removal. The stomata were observed to close under dark conditions for $\mathrm{C}_{3}$ plants. Therefore, TMA was mainly removed by stomata during daytime (light conditions). Moreover, the amount of wax may be another factor which decreased the concentration of TMA (Treesubsuntorn and Thiravetyan, 2012; Boraphech and Thiravetyan, 2015). As mentioned in the previous section, $S$. aureus had the lowest amount of waxes including epicuticular and cuticular wax. Thus, these waxes and the physical structure of the wax of $S$. aureus had low TMA removal efficiency under dark condition. It implied that these plants might be suitable for application only under light conditions.

Moreover, analysis of variance (ANOVA) was used to determine whether the differences between the species of plants and light conditions for TMA removal. According to Fig. 4, the results from ANOVA with 95\% confidence showed that different species of $\mathrm{C}_{3}$ plants including C. comosum, D. camilla, P. magnoliifolia, and S. aureus have no effect to TMA removal. However, different light conditions (i.e., LED, fluorescent, and dark conditions) have had a significant impact on TMA removal at $24 \mathrm{~h}$.

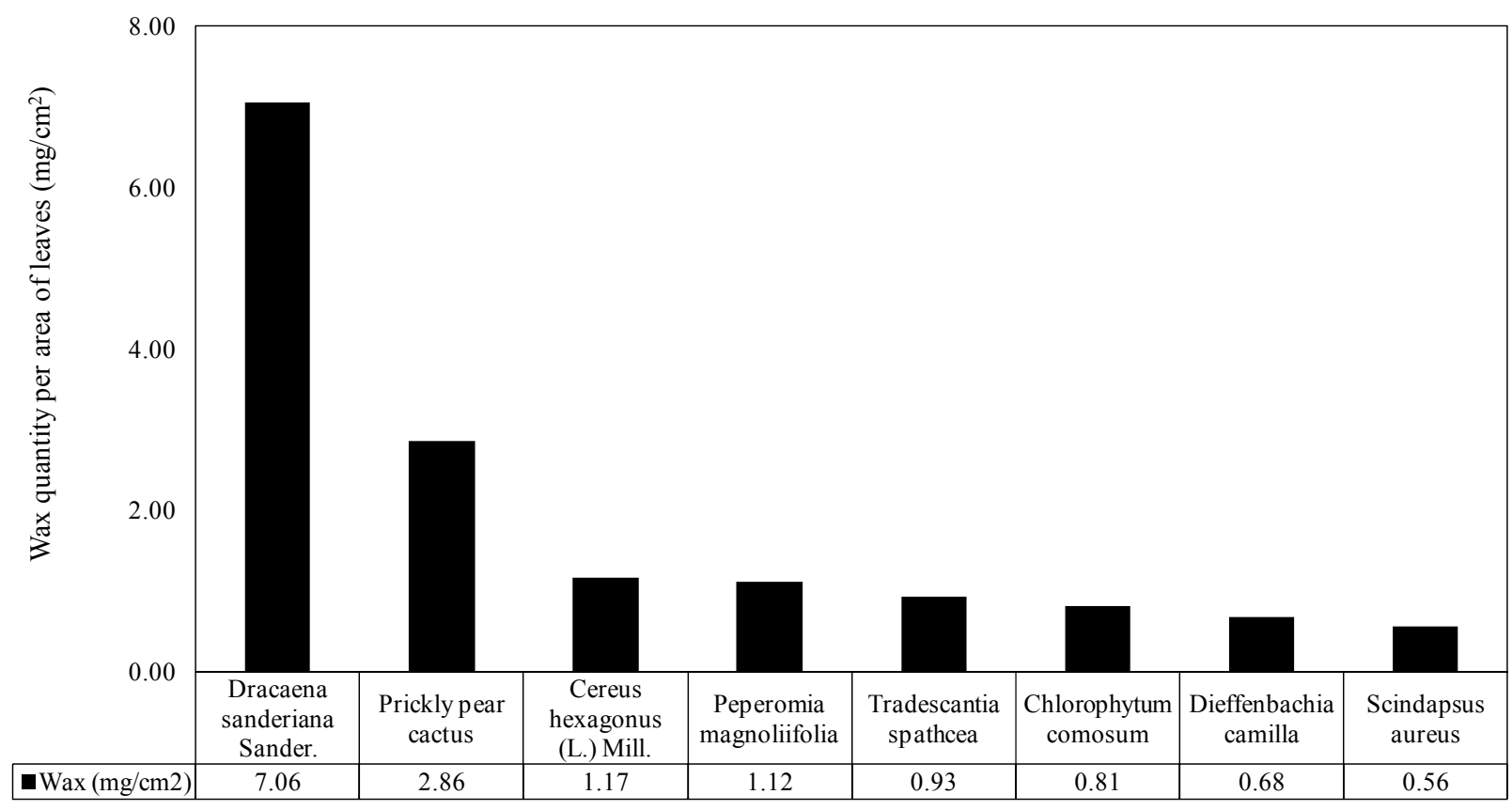

Fig. 3. Amount of cuticle wax per leaf area of various potted plants. 


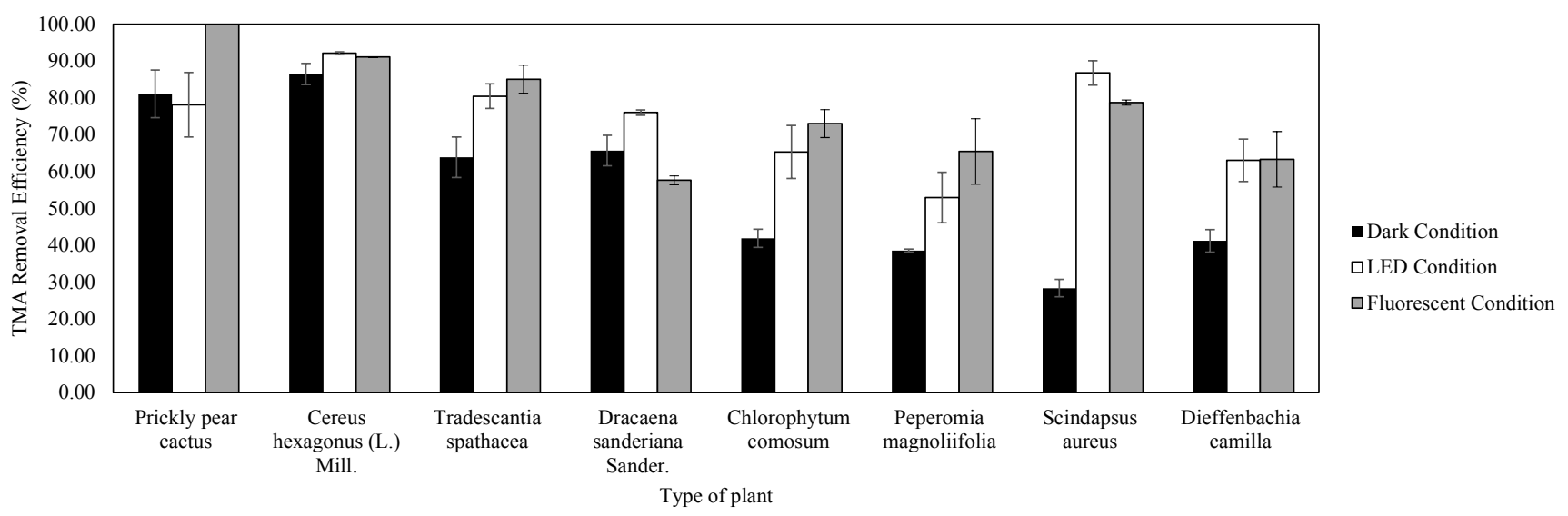

Fig. 4. TMA removal efficiency of 8 species of plant at $24 \mathrm{~h}$.

High Removal Efficiency under Light and Dark Conditions The plants in this group $\left(\mathrm{C}_{3}\right.$ and CAM plants), which were C. hexagonus (L.) Mill., Prickly pear cactus, D. sanderiana Sander, and T. spathacea, had high removal efficiency under light and dark conditions. The result showed that TMA removal efficiency for these four plants under light and dark conditions were quite similar, especially at $72 \mathrm{~h}$ ( $>90 \%$ removal). It indicated that light sources did not have a significant effect on these plants. For TMA removal, CAM plants (C. hexagonus (L.)Mill. and Prickly pear cactus) open stomata at night and absorb TMA. Therefore, CAM plants can reduce TMA under dark condition. Moreover, there are some species of $\mathrm{C}_{3}$ and $\mathrm{C}_{4}$ plants which can under stress conditions switch to the CAM system (facultative CAM). T. spathacea $\left(\mathrm{C}_{3}\right.$ plant) is included in facultative CAM. In case of $D$. sanderiana Sander, it had the highest amount of waxes including epicuticular and cuticular wax. Thus, these waxes and the physical structure of the wax may help for TMA removal under dark condition.

In addition, the results from ANOVA with 95\% confidence showed that different species of plants including C. hexagonus (L.) Mill., Prickly pear cactus, D. sanderiana Sander and T. spathacea and light conditions have no effect to TMA removal. It indicated that these 4 plants could remove TMA under dark and light conditions.

\section{CONCLUSIONS}

The results, the selected plants can be divided into two groups: (i) those with high TMA removal efficiency in light conditions and (ii) those with high removal efficiency in light and dark conditions. In the first group, $S$. aureus exhibited the highest removal efficiency. The main mechanism in this group $\left(\mathrm{C}_{3}\right.$ plants) was plant uptake via photosynthesis and open stomata during light conditions. In the second group, cactus type ( $C$. hexagonus (L.) Mill. and Prickly pear cactus) exhibited a high removal efficiency during both light and dark conditions. These plants (CAM) open their stomata at night and absorb TMA. Moreover, ANOVA results confirm, with $95 \%$ confidence, that the species of plant (chosen among 8 types) and the light conditions (viz., LED lighting, fluorescent lighting, or dark conditions) have a significant impact on TMA removal after $24 \mathrm{~h}$.

\section{ACKNOWLEDGMENTS}

This research was financially supported by the KMUTT Research Fund and Research Strengthening Project of Faculty of Engineering (King Mongkut's University of Technology Thonburi) and Thailand Research Fund with Office of The Higher Education Commission (Grant No. MRG5980109). The authors thank staffs from Environmental Engineering Department. The authors also thank Dr. Chairat Treesubsuntorn and Dr. Phattara Boraphech for their helps.

\section{SUPPLEMENTARY MATERIAL}

Supplementary data associated with this article can be found in the online version at http://www.aaqr.org.

\section{REFERENCES}

Boraphech, P. and Thiravetyan, P. (2015). Trimethylamine (Fishy odor) adsorption by biomaterials: Effect of fatty acids, alkanes, and aromatic compounds in waxes. $J$. Hazard. Mater. 284: 269-277.

Chang, C.T., Chen, B.Y., Shiu, I.S. and Jeng, F.T. (2004). Biofiltration of trimethylamine-containing waste gases by entrapped mixed microbial cells. Chemosphere 55: 751-756.

Chen, X.L., Guo, W.Z., Xue, X.Z., Wang, L.C. and Qiao, X.J. (2014). Growth and quality responses of 'GreenOak Leaf' lettuce as affected by monochromic or mixed radiation provided by fluorescent lamp (FL) and light emitting diode (LED). Sci. Hortic. 172: 168-175.

Chien, Y.C., Uang, S.N., Kuo, C.T., Shih, T.S. and Jen, J.F. (2000). Analytical method for monitoring airborne trimethylamine using solid phase micro-extraction and gas chromatography-flame ionization detection. Anal. Chim. Acta 419: 73-79.

Chung, J.P., Huang, C.T. and Dai, T.E. (2010). Spectral 
effects on embryogenesis and plantlet growth of Oncidium 'Gower Ramsey'. Sci. Hortic. 124: 511-516.

Chung, K.H. and Lee, K.Y. (2009). Removal of trimethylamine by absorption over zeolite catalysts and deodorization of fishy oil. J. Hazard. Mater. 172: 922927.

Ding, Y., Shi, J.T., Wu, W.X., Yin, J. and Chen, Y.X. (2007). Trimethylamine (TMA) biofiltration and transformation in biofilters. J. Hazard. Mater. 143: 341-348.

Drozdova, I.S., Bondar, V.V., Bukhov, N.G., Kotov, A.A., Kotva, M.M., Maevskaya, S.N. and Mokronosov, A.T. (2001). Effects of light spectral quality on morphogenesis and source-sink relations in radish plant, Russ. J. Plant Physiol. 48: 415-420.

Geraets, L., Bessems, J.G., Zeilmaker, M.J. and Bos, P.M. (2014). Human risk assessment of dermal and inhalation exposures to chemicals assessed by route-to-route extrapolation: The necessity of kinetic data. Regul. Toxicol. Pharm. 70: 54-62.

Ho, K.L., Chung, Y.C., Lin, Y.H. and Tseng, C.P. (2008). Biofiltration of trimethylamine, dimethylamine, and methylamine by immobilized Paracoccus sp. CP2 and Arthrobacter sp. CP1. Chemosphere 72: 250-256.

Kim, S.G., Bae, H.S. and Lee, S.T. (2011). A novel denitrifying bacterial isolate that degrades trimethylamine both aerobically and anaerobically via two different pathways. Arch. Microbiol. 176: 271-277.

Lin, K.H., Huang, M. Y., Huang, W.D., Hsu, M.H., Yang, Z.W. and Yang, C.M. (2013). The effects of red, blue, and white light-emitting diodes on the growth, development, and edible quality of hydroponically grown lettuce (Lactuca sativa L. var. capitata). Sci. Hortic. 150: 86-91.

Morh, H. and Browese, J. (1995). Plant physiology. Springer, Berlin.

Nhut, D.T., Hong, L.T.A., Watanabe, H., Goi, M. and Tanaka, M. (2003). Growth of banana plantlets cultured in vitro under red and blue light-emitting diode (LED) irradiation source. Acta Hortic. 575: 124-117.

NIOSH (1981). Occupational health guidelines for chemical hazards. DHHS (NIOSH) Publication, National Institute for Occupational Safety and Health, Ohio, USA.

Nobel, P.S. (1999). Physicochemical \& environmental plant physiology, 2nd edn. Academic Press, San Dieago.

OSHA (1994). Occupational safety and health guideline for trimethylamine, computerized information system, occupational safety and health administration. Department of Labor, Washington DC, USA.

Oyabu, T., Ayako, S., Onodera, T., Tanaka, K. and Wolverton, B.C. (2003). Characteristics of potted plants for removing offensive odors. Sens. Actuators, $B$ 89: 131-136.

Oyabu, T., Onodera, T., Kimura, H. and Sadaoka, Y. (2001). Purification ability of interior plant for removing of indoor-air polluting chemicals using a tin oxide gas sensor. J. Jpn. Soc. Atmos. Environ. 34: 319-325.

Richardson, A., Franke, R., Kersriens, G., Jarvis, M., Schreiber, L. and Fricke, W. (2005). Cuticular wax deposition in growing barley (Hordeum vulgare) leaves commences in relation to the point of emergence of epidermal cells from the sheaths of older leaves. Planta 222: 472-483.

Ruijten, M. (2005). Personal Communication from Dr. Marc Ruijten, National Institute of Public Health and Environment (RIVM), AEGL-2 Committee Member, The Netherlands.

Sintermann, J., Schallhardt, S., Kajos, M., Jocher, M., Bracher, A., Munger, A., Johnson, D., Neftel, A. and Ruuskanen, T. (2014). Trimethylamine emissions in animal husbandry. Biogeosciences 11: 5073-5085.

Sriprapat, W., Boraphech, P. and Thiravetyan, P. (2014) Factors affecting xylene-contaminated air removal by the ornamental plant, Zamioculcas zamiifolia. Environ. Sci. Pollut. Res. 21: 2603-2610.

Taiz, L. and Zeiger, E. (1998). Plant physiology, 2nd edn. Sinauer Associates, Inc., MA, USA.

Torok, A., Gulyas, Z., Szalai, G., Kocsy, G. and Majdik, C. (2015). Phytoremidiation capacity of aquatic plants is associated with the degree of phytochelatin polymerization. J. Hazard. Mater. 299: 371-378.

Treesubsuntorn, C. and Thiravetyan, P. (2012). Removal of benzene from indoor air by Dracaena sanderiana: Effect of wax and stomata. Atmos. Environ. 57: 317321.

Turker, O.C., Bocuk, H. and Yakar, A. (2013). The phytoremediation ability of a polyculture constructed wetland to treat boron from mine effluent. J. Hazard. Mater. 252-253: 132-141.

U.S. EPA (1999). Phytoremediation resource guide. EPA 542-B-99-003, Solid Waste and Emergency Response Technology Innovation Office, U.S. Environmental Protection Agency, Washington, DC, USA.

U.S. EPA (2006). Method 8260C (SW-846): Volatile Organic Compounds by Gas Chromatography/Mass Spectrometry (GC/MS). U.S. Environmental Protection Agency, Washington, DC, USA. http://www.epa.gov/ osw/hazard/testmethods/pdf/8260c.pdf.

Wolverton, B.C., Johnson, A. and Bounds, K. (1989). Interior landscape plants for indoor air pollution abatement. Final Report. NASA Stennis Space Centre, Mississippi, USA.

Wolverton, B.C. and Wolverton, J.D. (1993). Plants and soil microorganisms, removal of formaldehyde, xylene, and ammonia from the indoor environment. J. Miss. Acad. Sci. 38: 11-15.

Wolverton, B.C. (1996). How to grow fresh air. Penguin Book, New York, USA.

Wood, R.L., Orwell, R.L., Tarran, J. and Burchett, M.D. (2001). Pot-plants really do clean indoor air. The Nursery Papers, No. 2001/2, NIAA, Sydney, Australia.

Yang, D.S., Pennisi, S.V., Son, K. and Kays, S.J. (2009). Screening indoor plants for volatile organic pollutant removal efficiency. HortScience 44: 1381-133.

Yorio, N.C., Goins, G.D., Kagie, H.R., Wheeler, R.M. and Sager, J.C. (2011). Improving spinach, radish, and lettuce growth under red light-emitting diodes (LED) with blue light supplementation. HortScience 36: 380-383.

Zhu, J., Bundy, D.S., Li, X.W. and Rashid, N. (1997). 
Reduction of order and volatile substances in pig slurries by using pit additives. J. Environ. Sci. Health A 32: 605-619.
Received for review, September 10, 2018

Revised, December 21, 2018 Accepted, January 3, 2019 